\title{
ROTASI, MUTASI DAN PROMOSI DI PDAM KABUPATEN TANA TIDUNG
}

\author{
ROTATION, MUTATION AND PROMOTION AT PDAM \\ TANA TIDUNG REGENCY \\ Achmad Rivaldy Fajrie ${ }^{1)}$, Syahran ${ }^{2)}$ \\ ${ }^{1) 2}$ Universitas Borneo Tarakan \\ E mail : ${ }^{1)}$ Ahmadrivaldi33@gmail.com
}

\begin{abstract}
Abstrak : Penelitian ini merupakan penelitian kualitatif untuk meneliti rotasi, mutasi dan promosi di PDAM kabupaten tana tidung. Tujuan dari penelitian ini adalah untuk meneliti rotasi, mutasi dan promosi pegawai di pdam kabupaten tana tidung. Penelitian ini menggunakan pendekatan kualitatif dengan metode studi kasus. Data yang dianalisis adalah hasil wawancara direktur dan pegawai PDAM kabupaten tana tidung, serta telaah dokumen di PDAM kabupaten tana tidung. Dari hasil penelitian dapat diketahui bahwa rotasi di PDAM Kabupaten Tana Tidung sudah diterapkan dengan baik dan itu terbukti dengan adanya rotasi yang terjadi setiap 1 tahun sekali. Dari hasil observasi yang dilakukan peneliti, mutasi yang terjadi di PDAM Kabupaten Tana Tidung sudah terlaksana dengan baik karena dapat menerima pegawai dari luar daerah. Dari hasil peneltian pegawai yang di promosikan pada tahun 2015 berjumlah 1 orang yang diangkat menjadi Plt. Direktur PDAM Kabupaten Tana Tidung, dikarenakan pangkat pangkat yang sudah dianggap cukup untuk melaksanakan promosi.
\end{abstract}

Kata Kunci : Rotasi, Mutasi, Promosi

Abstract : This study used qualitative research to investigate rotation, mutation and promotion employee at PDAM Kabupaten Tana Tidung. The objective of this study was to investigate rotation, mutation and promotion in PDAM at Kabupaten Tana Tidung. This study used qualitative approach with study case method. Data analysis of this study were the result of interview of director and employee in PDAM at Kabupaten Tana Tidung and document analysis in PDAM at Kabupaten Tana Tidung. The result of this study was the rotation in PDAM at Kabupaten Tana Tidung has been implemented well and it is proven by the rotation that occurs every a year. From the result that conducted by the researcher, mutation that occurs in PDAM at Kabupaten Tana Tidung has been done well because it can accept the employees from the other region. From the result of this study the employee who was promoted in 2015 totaled one person and served as director in PDAM (Plt. Direktur PDAM Kabupaten Tana Tidung), because the position or degree is considered sufficient to carry out the promotion.

Keywords : Rotation, Mutation, Promotion 


\section{LATAR BELAKANG}

Mutasi pegawai merupakan kegiatan memindahkan pegawai dalam satu tingkat organisasi dari satu jabatan ke jabatan yang lainnya secara horizontal tanpa di ikuti adanya peningkatan gaji, tanggung jawab ataupun kekuasaan (Kadarman, 1997). Mutasi memiliki ruang lingkup yaitu mutasi yang vertikal yaitu (promosi), dan mutasi horizontal yaitu (rotasi). Promosi adalah apabila seseorang memiliki kinerja diatas standar organisasi dan berperilaku sangat baik yang diwujudkan dalam bentuk kenaikan karir atau jabatan. Dengan demikian yang mendapat promosi jabatan akan memperoleh tugas, wewenang dan tanggung jawab yang lebih besar. Secara horizontal yaitu rotasi, yaitu pemindahan pegawai kedivisi lain yang tidak disertai penambahan wewenang ataupun tanggung jawab.

\section{RUMUSAN MASALAH}

Adapun rumusan masalah yang peneliti ajukan adalah sebagai berikut: Bagaimana proses rotasi, mutasi dan promosi pegawai di PDAM Kabupaten Tana Tidung?

\section{TUJUAN PENELITIAN}

\footnotetext{
Penelitian ini dilakukan tentunya memiliki tujuan-tujuan tertentu. Adapun yang menjadi tujuan dilakukannya penelitian ini adalah : Untuk mengetahui proses rotasi, mutasi dan promosi pegawai di PDAM Kabupaten Tana Tidung.
}

\section{TINJAUAN PUSTAKA}

$$
\text { Wahyudi }
$$

merumuskan bahwa: "Suatu job rotation atau perputaran jabatan merupakan suatu mutasi personal yang dilakukan secara horizontal tanpa menimbulkan perubahan dalam hal gaji ataupun pangkat atau golongan dengan tujuan untuk menambah pengetahuan dan pengalaman serta untuk menghindari kejenuhan". Hasibuan (2003) mengemukakan pendapatnya tentang rotasi jabatan sebagai berikut: "Rotasi jabatan adalah suatu perubahan posisi/jabatan yang dilakukan secara horizontal/vertikal di dalam suatu organisasi". Mutasi memiliki banyak arti yang dijelaskan oleh para ahli. Hasibuan (2008) mengungkapkan bahwa Mutasi adalah suatu perubahan posisi, jabatan, tempat, pekerjaan yang dilakukan baik secara horizontal maupun vertikal (promosi/demosi) di dalam suatu organisasi. Pada dasarnya mutasi termasuk dalam fungsi pengembangan pegawai, karena tujuannya untuk meningkatkan eisiensi dan efektivitas kerja dalam perusahaan (pemerintahan). Nitisemito (2003) menyatakan Promosi adalah kegiatan pemindahan karyawan, dari satu jabatan kejabatan lain yang lebih tinggi. Dengan demikian, promosi akan selalu diikuti oleh tugas, tanggung jawab, dan wewenang yang lebih tinggi dari jabatan yang diduduki sebelumnya. Selanjutnya, pada umumnya promosi juga diikuti dengan peningkatan income serta fasilitas yang lain. Tetapi, promosi itu sendiri sebenarnya mempunyai nilai, karena promosi adalah 
merupakan bukti pengakuan antara lain terhadap prestasinya.

\section{METODOLOGI PENELITIAN}

Metode yang digunakan pada penelitian ini adalah kualitatif studi kasus. Creswell (2010) mendefinisikan metode penelitian kualitatif sebagai suatu pendekatan atau penelusuran untuk mengeksplorasi dan memahami suatu gejala sentral. Patton (2007) mendefinisikan studi kasus sebagai upaya mengumpulkan dan kemudian mengorganisasikan serta menganalisis data tentang kasuskasus tertentu berkenaan dengan permasalahan-permasalahan yang menjadi perhatian peneliti untuk kemudian data tersebut disbandingbandingkan atau dihubunghubungkan satu dengan lainnya (dalam hal lebih dari satu kasus) dengan tetap berpegang pada prinsip holistic dan kontekstual. Fokus penelitian sangat penting dalam penelitian kualitatif. Adanya fokus penelitian bertujuan agar dapat membatasi studi dan bidang penelitian. Tanpa adanya fokus penelitian, peneliti akan terjebak dalam melimpahnya volume data yang diperoleh di lapangan.

Penentuan fokus suatu penelitian memiliki dua tujuan, yaitu:

1. Penetapan fokus membatasi studi yang berarti bahwa dengan adanya fokus, penentuan tempat penelitian menjadi lebih layak.

2. Penentuan fokus secara efektif menetapkan kriteria untuk menyaring informasi yang masuk. $\underline{\text { Jenis dan Sumber Data }}$

Jenis data yang digunakan pada penelitian ini adalah data primer dan sekunder. Waluya (2007) mendefinisikan data primer sebagai data atau keterangan yang diperoleh peneliti secara langsung. Data sekunder adalah keterangan yang diperoleh dari pihak kedua, baik berupa orang maupun catatan, seperti buku, laporan, bulletin, dan majalah yang sifatnya dokumentasi. Data primer yang digunakan pada penelitian ini adalah hasil observasi dan wawancara terstruktur kepada informan. Data sekunder yang digunakan pada penelitian ini adalah hasil dokumentasi dan studi pustaka. Moleong (2007) menjelaskan bahwa sumber data utama dalam penelitian kualitatif adalah kata-kata dan tindakan, selebihnya adalah data tambahan seperti dokumen, dan lainlain.

Berdasarkan masalah dan fokus penelitian, sumber data dalam penelitian ini diklasifikasikan menjadi tiga jenis, yang disingkat dengan 3P, yaitu:

1. Person (orang), yaitu responden yang ditanyai oleh peneliti mengenai variabel yang diteliti. Person dalam penelitian ini adalah direktur dan pegawai PDAM Kabupaten Tana Tidung.

2. Paper (kertas), yaitu dokumen, surat keterangan, arsip, pedoman, dan surat keputusan (SK). Data yang digunakan dalam penelitian ini berhubungan dengan peraturan perundang-undangan, buku profil, dan bacaan yang menunjang teori.

3. Place (tempat), yaitu sumber data mengenai keadaan di tempat 
berlangsungnya suatu kegiatan yang berhubungan dengan penelitian. Place dalam penelitian ini adalah PDAM di Kabupaten Tana Tidung.

\section{HASIL DAN PEMBAHASAN}

\begin{abstract}
Kabupaten Tana Tidung adalah salah satu kabupaten di Provinsi Kalimantan Utara, Indonesia, yang disetujui pembentukannya pada Sidang Paripurna DPR RI pada tanggal 17 Juli 2007. Kabupaten ini merupakan pemekaran dari 3 wilayah kecamatan di Kupaten Bulungan, Kalimantan Timur, yakni Kecamatan Sesayap, Sesayap Hilir dan Tanah Lia. Sejak tahun 2012, kabupaten ini merupakan bagian dari Provinsi Kalimantan Utara, seiring dengan pemekaran provinsi baru tersebut dari Provinsi Kalimantan Timur. Nama Ibukota Kabupaten ini memang unik dengan ejaannya yang khas Tideng Nama Tideng Pale berasal dari dua kosa kata yakni "Tideng" dan "Pale". Dalam Bahasa Tidung "Tideng" artinya Gunung sementara "Pale" berarti "Tawar atau Hambar", jika disatukan maka bermakna "Gunung Hambar". Gunung Hambar bermaksud kepada gunung yang dibawah kaki gunung tersebut mengalir Sungai Sesayap.
\end{abstract}

$\underline{\text { Rotasi }}$

$$
\text { Berdasarkan data Rotasi }
$$
PDAM di Kabupaten Tana tidung pada tahun 2015 pegawai PDAM Kabupaten Tana Tidung merotasikan pegawainya sebanyak 6 orang pegawai, pada tahun 2016 tidak melakukan rotasi dikarenakan masih belum optimalnya kinerja yang dilakukan oleh pegawai PDAM, dan pada tahun 2017-2018 mengalami rotasi karena masuk nya beberapa pegawai honorer sehingga untuk meningkatkan kinerja pegawai dan menambahkan wawasan kepada pegawai honorer maka PDAM melaksanakan rotasi. Jadi PDAM Kabupaten Tana Tidung setiap tahun merotasikan pegawainya agar tidak jenuh pada suatu pekerjaan telah sesuai pernyataan Hasibuan (2003) rotasi jabatan adalah suatu perubahan posisi/jabatan yang dilakukan secara horizontal/vertikal di dalam suatu organisasi.

\section{Mutasi}

Berdasarkan data Mutasi ke PDAM Tana Tidung, pegawai yang di mutasi kan ke PDAM Kabupaten Tana Tidung berasal dari Tanjung Selor 2 orang dan berau 1 orang untuk mengisi IKK (Istalasi Kota Kabupaten) yang ada di Kabupaten Tana Tidung, seperti yang dikatakan Hasibuan (2008) mutasi adalah suatu perubahanposisi/jabatan/tempat/peke rjaan yang dilakukan baik secara horizontal maupun vertikal di dalam satu organisasi.

\section{$\underline{\text { Promosi }}$}

Dari data Rotasi di PDAM Tana Tidung, pegawai yang di promosikan pada tahun 2015 berjumlah 1 orang yang diangkat menjadi Plt. Direktur PDAM Kabupaten Tana Tidung, dikarenakan pangkat pangkat yang sudah dianggap cukup untuk melaksanakan promosi, promosi selanjutnya pada tahun 2017 
pengangkatan menjadi Direktur difinitif PDAM Kabupaten Tana Tidung.

\section{$\underline{\text { Pembahasan }}$}

Analisis jabatan merupakan proses yang tersusun sistematis dengan cara mengumpulakan berbagai informasi yang bersumber dari tanggung jawab, tugas, dan kewajiban pada pekerjaan tertentu, analisa jabatan yang disusun sistematis melingkupi berbagai kegiatan diantaranya mengorganisasikan, mengevaluasi, dan mengumpulkan jabatan maupun pekerjaan. Langkah yang harus dilakukan sebelum melakukan kegiatan analisis jabatan adalah menginvetarisasi jabatan guna mendata berapa banyak jabatan yang terdapat di dalam sebuah perusahaan. Selain itu, perlu juga untuk mempelajari materi berupa struktur organisasi dari perusahaan. Hal yang perlu untuk dilakukan adalah melakukan pendataan berbagai jabatan yang terdapat pada struktur organisasi. Sementara itu, struktur organisasi memang perlu untuk dilakukan pengkajian dibanding dengan perihal beban kerja dan hal lainnya. Berbagai hal tersebut diantaranya kebutuhan pengembangan akan karier dari pegawai dan keselarasan dengan ragam kebutuhan pada peningkatan produktivitas.

Hal terakhir adalah kebutuhan akan pengembangan organisasi yang disesuaikan dengan pengembangan pada usaha. Apabila dalam sebuah perusahaan tidak terdapat struktur organisasi formal, maka bersumber dari inventarisasi jabatan bisa disusun sebuah bagan struktur dari jabatan yang bersifat sementara. Hasil ini kemudian perlu untuk disesuaikan kembali terhadap kondisi yang memang dibutuhkan sesudah adanya proses dari analisis jabatan dimana telah selesai untuk dilakukan.

Dari hasil penelitian dapat diketahui bahwa rotasi di PDAM Kabupaten Tana Tidung sudah diterapkan dengan baik dan itu terbukti dengan adanya rotasi yang terjadi setiap 1 tahun sekali yang ditunjang dengan data yang ada pada (gambar 4.1) dan didukung oleh beberapa wawancara yang menyatakan bahwa rotasi merupakan suatu proses penyegara agar pegawai tidak jenuh pada suatu bagian tertentu dan juga didukung oleh pernyataan Hasibuan (2003) Rotasi jabatan adalah suatu perubahan posisi/jabatan yang dilakukan secara horizontal/vertikal di dalam suatu organisasi.

Dari hasil observasi yang dilakukan peneliti di PDAM Kabupaten Tana Tidung adalah pola rotasi yang terjadi di PDAM masih banyak kesamaan dalam alasan mengapa mereka di rotasikan mayoritas menjawab sudah lama dibagian tersebut dan beberapa juga menjawab untuk menambah wawasan mereka di bagian pekerjaan yang lain dan ada pegawai yang mengatakan bahwa ini sudah merupakan tuntutan kantor untuk meningkatkan kinerja pegawainya.

Dari hasil penelitian mutasi yang terjadi di PDAM Kabupaten Tana Tidung sudah terlaksana dengan baik yang didukung dengan data pada (gambar 4.2) dan didukung dengan hasil wawancara yang 
menyatakan bahwa mutasi yang terjadi merupakan kewajiban yang harus dilaksanakan karena murapakan bagian dari sumpah jabatan. Hasil penelitian juga sesuai dengan pernyataan Sastrohadiwiryo (2003) mutasi adalah kegiatan ketenagakerjaan yang berhubungan dengan proses pemindahan fungsi, tanggung jawab, dan status ketenagakerjaan tenaga kerja ke situasi tertentu dengan tujuan agar tenaga kerja yang bersangkutan memperoleh kepuasan kerja yang mendalam dan dapat memberikan prestasi kerja yang semaksimal mungkin kepada perusahaan. Dari hasil observasi yang dilakukan peneliti, mutasi yang terjadi di PDAM Kabupaten Tana Tidung sudah terlaksana dengan baik karena dapat menerima pegawai dari luar daerah, meskipun di PDAM itu sendiri masih banyak kekurangan namun dapat menerima pegawai dari luar daerah, ini merupakan keuntungan dimana pegawai dari luar daerah dapat berbagi ilmu dan pengalaman kepada para pegawai PDAM Kabupaten Tana Tidung. Dari hasil peneltian pegawai yang di promosikan pada tahun 2015 berjumlah 1 orang yang diangkat menjadi Plt. Direktur PDAM Kabupaten Tana Tidung, dikarenakan pangkat pangkat yang sudah dianggap cukup untuk melaksanakan promosi, promosi selanjutnya pada tahun 2017 pengangkatan menjadi Direktur difinitif PDAM Kabupaten Tana Tidung dan didukung oleh data pada (gambar 4.3) dan hasil wawancara juga didukung oleh pernyataan Nitisemito (2003) Promosi adalah kegiatan pemindahan karyawan, dari satu jabatan kejabatan lain yang lebih tinggi. Dengan demikian, promosi akan selalu diikuti oleh tugas, tanggung jawab, dan wewenang yang lebih tinggi dari jabatan yang diduduki sebelumnya.

43

Dari observasi yang dilakukan peneliti pada PDAM Kabupaten Tana Tidung masih banyak kekurangan dalam struktur organisasi yang disebabkan oleh kurangnya sumber daya yang memiliki stadarisasi dalam suatu pekerjaan tertentu. Karena yang mengisi jabatan tertentu pada PDAM haru memiliki kompetensi yang terstruktur dengan sertifikasi pada bidang tertentu, selain itu PDAM di Kabupaten Tana Tidung merupakan kabupaten baru di daerah Kalimantan Utara masih banyak permasalahan yang harus dibenahi.

\section{KESIMPULAN DAN SARAN}

$\underline{\text { Kesimpulan }}$

Penelitian ini merupakan
studi yang bertujuan untuk
mengetahui bagaimana Proses
Rotasi, Mutasi dan Promosi di Pdam
Kabupaten Tana Tidung.
Berdasarkan hasil wawancara,
observasi dan pembahasan, maka
dapat ditarik beberapa kesimpulan
sebagai berikut:

1. Rotasi yang dilakukan di Perusahaan Daerah Kabupaten Tana Tidung telah sesuai dengan prinsip prinsip dasar teori rotasi yaitu perpindahan pegawai terjadi dalam satu tingkatan.

2. Mutasi yang terjadi di Perusahaan Daerah Kabupaten Tana Tidung sudah sesuai 
dengan teori mutasi yaitu perpindahan tempat bekerja.

3. Promosi yang dialami oleh responden telah sesuai dengan prinsip dari teori promosi yaitu terjadi kenaikan jabatan yang diikuti dengan bertambahnya kekuasaan dan tanggung jawab pegawai.

$\underline{\text { Saran }}$

\begin{tabular}{l}
\multicolumn{3}{c}{ Berdasarkan dari kesimpulan } \\
penelitian ini, maka $r$ dapat \\
dikemukkan saran-saran sebagai \\
berikut:
\end{tabular}

1. Penting bagi perusahaan untuk meningkatkan suatu kinerja karyawan sehingga menimbulkan dampak yang baik untuk mencapai tujuan perusahaan. Untuk pegawai agar meningkatkan kinerjanya agar dapat di promosikan oleh perusahaan.

2. Bagi peneliti selanjutnya yang akan mengambil judul penelitian yang sama sebaiknya menggunakan metode yang berbeda, objek berbeda, objek penelitian berbeda dan mengembangkan variabel dengan indikator lain yang tidak ada pada penelitian ini.

\section{DAFTAR PUSTAKA}

Hasibuan, Malayu. S.P. 2002. Manajemen Sumber Daya Manusia. Jakarta: PT. Bumi Aksara.

Hasibuan, Malayu. S.P. 2003. Manajemen Sumber Daya Manusia, Edisi Revisi. Jakarta: PT. Bumi Aksara.
Hasibuan, Malayu. S.P. 2008. Manajemen Sumber Daya Manusia. Jakarta: PT. Bumi Aksara. Hasibuan, Malayu. S.P 2009. Manajemen Sumber Daya Manusia, Edisi Revisi. Jakarta: PT. Bumi Aksara.

Kadarman, AM, SJ. 1997. Pengantar Ilmu Manajemen. Jakarta: PT Gramedia Pustaka Utama.

Kaymaz, K. 2010. The Effect Job Rotation Pratices on Motivation: A Research on Managers in the Automotive Organizations. Business and Economics Research Journal, Volume 1 Number 3: 59-85. Moleong,

Lexy J. 2001. Metodologi Penelitian Kualitatif. Bandung: Remaja Rosdakarya. Mangkuprawira, TB.

Sjafri. 2004. Manajemen Sumber Daya Manusia, Strategik. Jakarta : Ghalia Indonesia.

Maulansyah, Khair Alam. 2016.

Pengembangan Kapasitas Aparatur di Daerah Otonom Baru. Malang: Universitas Brawijaya.

Nitisemito, Alex, S. 2003. Manajemen Personalia. Jakarta : Ghalia Indonesia.

Nurbaiti, Amalia. 2013. Implementasi Knowledge Sharing Terhadap Kinerja Pustakawan di Kantor Perpustakaan, Arsip dan Dokumentasi Kabupaten Sukoharjo. Semarang: Undip Repository.

Pawito. 2007. Penelitian Komunikasi Kualitatif. Yogyakarta: LKiS Pelangi Aksara. 
Peraturan Pemerintah Nomor 12 Tahun 2002 Jenis-Jenis Promosi Pegawai. Peraturan Pemerintah Nomor 43 Tahun 1999, tentang Pokok- Pokok Kepegawaian (Lembaga Negara Republik Indonesia Tahun 1999 Nomor 169, Tambahan Lembaran Negara Republik Indonesia Nomor 3890).

Pratiwi, Bunga Ika, Hakim dan Sisdiwiyanto. 2013.

Pelaksanaa Mutasi Pegawai di kota Batu (Studi pada Badan Kepegawaian Daerah Kota Batu). Jurnal Administrasi Publik, Halaman 771-776.

Rivai, Veithzal. 2004. Manajemen Sumber Daya Manusia Untuk Perusahaan: Dari Teori Ke Praktik. Jakarta : PT. Raja Grafindo Persada.

Santoso, Budi dan Ahmad Riyadi. 2012. Rotasi, Mutasi, dan Promosi Karyawan di Kantor Pelayanan Pajak Pratama Klaten. Jurnal Ekonomi Manajemen Sumber Daya Manusia, Halaman 26-34.

Semiawan, Conny R, Jozef Raco. 2010. Metode Penelitian Kualitatif, Jenis, Karakteristik, dan Keunggulannya. Jakarta: Grasindo

Siagian, Sondang P. 2013. Manajemen Sumber daya Manusia. Jakarta: PT. Bumi Aksara.

Sudin, Alwi. 2001. Pengaruh Kepemimpinan, Motivasi, dan Lingkungan Kerja terhadap Kinerja Pegawai Kecamatan Laweyan Kota
Surakarta. Jurnal Manajemen Sumber Daya Manusia, Volume 4 Nomor 1 : 1-8.

Sastrohadiwiryo, B.S. 2003. Manajemen Tenaga Kerja Indonesia, Edisi 2. Jakarta: PT. Bumi Aksara

Sastrohadiwiryo, B.S. 2005. Manajemen Tenaga Kerja Indonesia. Jakarta: PT. Bumi Aksara.

Simamora, Henry. 2004. Manajemen Sumber Daya Manusia, Edisi 3. Yogyakarta : STIE YKPN.

Semiawan, Conny R, Jozef Raco. 2010. Metode Penelitian Kualitatif, Jenis, Karakteristik, dan Keunggulannya. Jakarta: Grasindo.

Singarimbun, Efendi. 2007. Metode Penelitian Survei. Jakarta: LP3ES.

Siswandi. 1999. Manajemen Sumber Daya Manusia. (http://sebabsebab mutasi pegawai.com diakses tanggal 16 November 2017.

Simamora, Henry. 1999. Manajemen Sumber Daya Manusia, Edisi 3. Yogyakarta : STIE YKPN. Singarimbun, Efendi. 2008. Metode Penelitian Survei. Jakarta: LP3ES.

Ulfa, F. 2013. Pelaksanaan Mutasi Transfer dan promosi Pegawai Negeri Sipil Pada Sekretariat Daerah Di Kabupaten Kapuas. Jurnal Ilmu Politik dan Pemerintahan Lokal, Halaman 276-286.

Undang-Undang Republik Indonesia Nomor 41 Tahun 2007 Tentang APARATUR SIPIL 
NEGARA. Jakarta: Badan

Kepegawaian Negara.

Wandasari, Kartika, S. R. (n.d.). 2016. Pengaruh Mutasi

Jabatan terhadap Prestasi

Kerja PNS di Sekretariat

Badan Pengawas

Perdagangan Berjangka

Komoditi. Jurnal

Administrasi Bisnis Terapan

Poleteknik Negeri Jakarta.

Wahyudi, B. 2002. Manajemen

Sumber Daya Manusia.

Bandung: Sulita.

Waluya, Bagja. 2007. Sosiologi : Menyelami Fenomena Sosial di Masyarakat. Bandung:

Setia Purna Inves. 
